\title{
MECHANICAL AND CHEMICAL ACTIVATION OF BLAST FURNACE SLAG AND ITS INFLUENCE ON THE MECHANICAL PROPERTIES OF THE RESULTING CEMENT PASTE
}

\author{
Jan Horych*, Pavel Tesárek, ZdenĚK ProšEK \\ Czech Technical University in Prague, Faculty of Civil Engineering, Department of Mechanics, Thákurova 7, \\ 16629 Prague 6, Czech Republic \\ * corresponding author: jan.horych@fsv.cvut.cz
}

\begin{abstract}
The usage of waste materials is a very important global topic. The large amount of waste everywhere in the world needs to be processed or disposed. Landfilling is not an option anymore, because of European legislation and restrictions. A lot of studies are trying to develop new options or possibilities of using waste materials. This research is trying to find a way to process blast furnace slag. A high-speed mill was used for the mechanical activation. Chemical activation was used as the next step of activation. There are many materials that could be used, but in this study we used slaked lime and water-glass. Slaked lime had a positive effect on mechanical properties. Samples had higher compressive strength but the effect was limited only for 5 wt. \%. Another used material was water-glass, but in this case, there was a significant negative effect. Compressive strength and flexural strength were significantly reduced.
\end{abstract}

KEYWORDS: Activation, blast furnace slag, cement replacement, slaked lime, water-glass.

\section{INTRODUCTION}

The objective of this study is to find a way to replace cement from concrete with useless waste materials. According to the trend of recycling we tried to find an option to use old and highly carbonated blast furnace slag as a partial substitute for Portland cement. Concrete is a trendy material thanks to its variability and reliability. Cement is the main and the most important ingredient of concrete, but it is also the most expensive ingredient from natural resources. The production itself is highly economically and ecologically demanding. An issue with cement is not a new topic. For example, Bellmann F. and Stark J. [1] focused on chemical activation of blast furnace slag by adding calcium hydroxide and soluble calcium salts such as calcium chloride, calcium bromide, calcium nitrate, calcium formate and calcium acetate. Early compressive strength was measured on mortar samples. Compressive strength was increased by adding calcium hydroxide, calcium carbonate and calcium acetate from $3 \mathrm{MPa}$ to $25 \mathrm{MPa}$ after 7 days. After the 28 days period the final compressive strength was increased from $36 \mathrm{MPa}$ to $53 \mathrm{MPa}$. Another research from Yum W. et al. [2] investigated the influence of calcium formate on the strength and microstructure of the ground granulated blast furnace slag activated with calcium oxide. The next study shows the effect of different slag characteristics on compressive strength in slag system with calcium oxide activation written by Jeong Y. et al. in 2016 [3]. Four kinds of ground granulated blast furnace slags from different sources were collected to investigate changes in final mechanical properties. Each of the slags developed significantly different compressive strength regardless of seemingly similar characteristics of the slags. The values of the final compressive strengths were spread from $25 \mathrm{MPa}$ up to $52 \mathrm{MPa}$ in 28 days. The reaction products were different as well. The goal of the study by Wang Y. et al. [4] was to determine the effect of wet grinding on the mechanical properties of blast furnace slag and slag-cement mixtures. Testing was focused on different grinding times from $10 \mathrm{~min}$ to $50 \mathrm{~min}$ in $10 \mathrm{~min}$ intervals. The performance of well ground samples of slag indicated the effectiveness of wet grinding. The $50 \mathrm{~min}$ grinding could decrease the average particle size to $2.95 \mu \mathrm{m}$. Other effects were high reactivity, improvement of mechanical properties and reduction of porosity. Research of Escalante-García J. et al. [5] observed a mechanically activated granulated blast furnace slag. Samples were composed in a range of 50 to $95 \mathrm{wt}$. \% to replace clinker in Portland slag cement. Structural properties were determined using X-ray diffraction, electron microscopy, thermogravimetry and differential thermal analysis. Up to the $70 \mathrm{wt}$. \% replacement was found an improvement of compressive strength in the first and 28th day. Microstructural changes of the slag caused by mechanical activation provided enhanced reactivity and the improvement of cement strength. The paper from Sobolev K. [6] examined the effect of grinding on high-performance cement containing granulated blast furnace slag. Samples were produced in high volumes of blast furnace slag. Testing results of mortars based on modified cement improved compressive strength up to $91.7 \mathrm{MPa}$. Final mechanical properties were increased by $62 \%$ over the reference sample. 


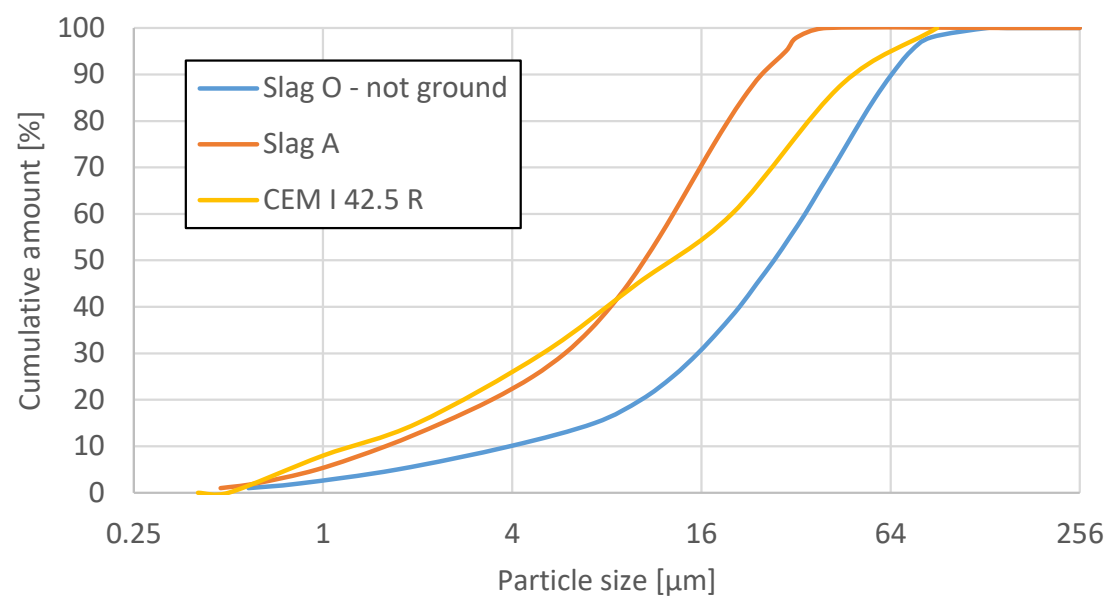

Figure 1. Particle size distribution of used materials.

\begin{tabular}{ccccccc}
\hline Mixtures & $\begin{array}{c}\text { Cement } \\
{[\text { wt. \% }]}\end{array}$ & $\begin{array}{c}\text { Slag } \\
{[\mathrm{wt.} \%]}\end{array}$ & $\begin{array}{c}\text { Type } \\
\text { of slag }\end{array}$ & $\begin{array}{c}\text { Slaked Lime } \\
{[\mathrm{wt.} \%]}\end{array}$ & $\begin{array}{c}\text { w/b } \\
{[-]}\end{array}$ & $\begin{array}{c}\text { Bulk density } \\
{\left[\mathrm{kg} / \mathrm{m}^{3}\right]}\end{array}$ \\
\hline C100 & 100.0 & - & - & - & 0.40 & $2020 \pm 10$ \\
O30/A0 & 70.0 & 30.0 & O & - & 0.40 & $1978 \pm 29$ \\
O30/AV5 & 67.5 & 27.5 & O & 5 & 0.40 & $1958 \pm 17$ \\
O30/AV10 & 65.0 & 25.0 & O & 10 & 0.40 & $1940 \pm 9$ \\
A30/A0 & 70.0 & 30.0 & A & - & 0.40 & $1992 \pm 28$ \\
A30/AV5 & 67.5 & 27.5 & A & 5 & 0.40 & $1998 \pm 22$ \\
A30/AV10 & 65.0 & 25.0 & A & 10 & 0.40 & $1942 \pm 25$ \\
\hline
\end{tabular}

TABLE 1. Composition of individual samples with slaked lime.

\section{MATERIALS AND SAMPLES}

During the research, Portland cement was still a basic component. Specifically, it was Portland cement CEM I 42.5 R from Radotín. Another component was blast furnace slag. The source of slag was a foundry industry complex in Kladno. It was a waste from slag aggregate production by recycling. Used slag was approximately 100 years old air-cooled and carbonated blast furnace slag stored on a heap. At first, waste materials were not immediately ready for another use. It needed to be activated. As mentioned, mechanical activation was used on the base of previous study of Prošek Z. [7]. Collaboration with Lavaris Ltd. was used again. The main goal was to find a material useable as a chemical activator of waste materials. Dimensions of all produced samples were $40 \times 40 \times 160 \mathrm{~mm}$. They were stored in water for 28 days. During this time, we tested every sample with non-destructive methods to determine dynamic Young's modulus of elasticity and dynamic shear modulus. At the end of this period, samples were destroyed with a destructive bending test and compression test to confirm final mechanical properties. Slaked lime was used for the first experiment. In this test we also used two samples of slag with the different grinding capacity to find an ideal option and investigate the synergy of mechanical and chemical activation.

Figure 1 shows the difference between individual samples of the slags. The slag with no grinding was called Slag O. As we can see, slag A was ground and the particle size distribution changed significantly and is similar to the curve of the reference cement CEM I 42.5 R. Samples were composed of changing shares of Portland cement 65 to 100 wt. \%, 25 to 30 wt. $\%$ of blast furnace slag and 0 to 10 wt. $\%$ of slaked lime (Table 1$)$. Water binder ratio $(\mathrm{w} / \mathrm{b})$ was always set on 0.4 .

In the second phase water-glass was used based on sodium and potassium. The composition of samples was similar to the previous tests. There was 65 to 100 wt. $\%$ of Portland cement, 25 to 30 wt. $\%$ of blast furnace slag and 0 to 10 wt. $\%$ of the activator (Table 2 ). Based on the results of the first phase, testing samples were produced using only slag A.

\section{Measurement methods}

Several methods were used through testing to investigate mechanical properties. First of them was a nondestructive resonance method. In period of 28 days dynamic Young's modulus of elasticity and dynamic shear modulus were determined every week. A set of instruments and devices was used to measure natural frequency of all samples in longitudinal, transverse 




Figure 2. Development of dynamic Young's modulus of the samples with slaked lime.

\begin{tabular}{cccccc}
\hline Mixtures & $\begin{array}{c}\text { Cement } \\
\text { [wt. \%] }\end{array}$ & $\begin{array}{c}\text { Slag } \\
{[\mathrm{wt} . \%]}\end{array}$ & $\begin{array}{c}\text { Sodium } \\
\text { Silicate [wt. \%] }\end{array}$ & $\begin{array}{c}\text { Potassium } \\
\text { Silicate [wt. \%] }\end{array}$ & $\begin{array}{c}\text { Bulk density } \\
{\left[\mathrm{kg} / \mathrm{m}^{3}\right]}\end{array}$ \\
\hline C100 & 100.0 & - & - & - & $2020 \pm 10$ \\
A30/A0 & 70.0 & 30.0 & - & - & $1969 \pm 36$ \\
A30/AN5 & 67.5 & 27.5 & 5 & - & $1963 \pm 27$ \\
A30/AN10 & 65.0 & 25.0 & 10 & - & $1899 \pm 10$ \\
A30/AK5 & 67.5 & 27.5 & - & 10 & $1945 \pm 8$ \\
A30/AK10 & 65.0 & 25.0 & - & $1899 \pm 13$ \\
\hline
\end{tabular}

TABLE 2. Composition of individual samples with water-glass.

and torsional oscillation. The supports of samples were soft and elastic pads and had to be at node lines of basic natural mode shapes. Impact hammer type 8206 was used to excite vibration of the samples. Acceleration transducer type Brüel \& Kjær type 4519-003 measured the response of the samples. Both of devices are connected to the measurement station 3560-B-X12. It's purpose is to record the excitation and response signals. The station transforms received signals to the frequency domain using the Fast Fourier Transform. Computer with specific software called PULSE LabShop then creates a frequency response function. The dynamic modulus of elasticity and the dynamic shear modulus were calculated according to ASTM 1876-01 and ČSN 731372 [8, 9]. The measurement of the dynamic modulus of elasticity and the dynamic shear modulus was taken from the work of J. Topič [10].

The flexural strength was measured at the end of the 28 days period by using three-point bending test on samples measuring $40 \times 40 \times 160 \mathrm{~mm}$. Samples were broken approximately in half $(40 \times 40 \times \sim 80 \mathrm{~mm})$. The loading through the testing was displacement controlled at a constant rate of $1 \mathrm{~mm} / \mathrm{min}$. The distance between the supports was $100 \mathrm{~mm}$. Then these halves were used to determine compressive strength by uniaxial compression test. Uniaxial compression testing was displacement controlled at a rate of $5 \mathrm{~mm} / \mathrm{min}[11,12]$.

\section{Results And Discussion}

As mentioned through testing, the development of Young's dynamic modulus and dynamic shear modulus was measured for all samples. In the first phase of the experiment, slaked lime was used to activate blast furnace slag. Figure 2 shows the development of dynamic Young's modulus. First we can see a difference approximately $4 \mathrm{GPa}$ between a reference sample with 100 wt. \% of Portland cement and the rest of the samples. It is caused by the replacement of Portland cement with blast furnace slag. Another slight difference, we can see between samples with a lower amount of slaked lime. Samples A 30/AV0, A 30/AV5 and O 30/AV0 had a little bit higher values of dynamic Young's modulus and dynamic shear modulus (Figure 3 ). The highest progress of both modules was registered in first 7 days. Later testing from day 7 to day 21 showed lower improvement. In the last week of testing, values were almost the same. Results of non-destructive testing suggest there was an influence of mechanical activation. Slag A had a slightly higher both dynamic Young's modulus and dynamic shear modulus. Also, the effect of slaked lime as an activator was limited. Only 5 wt. \% of 


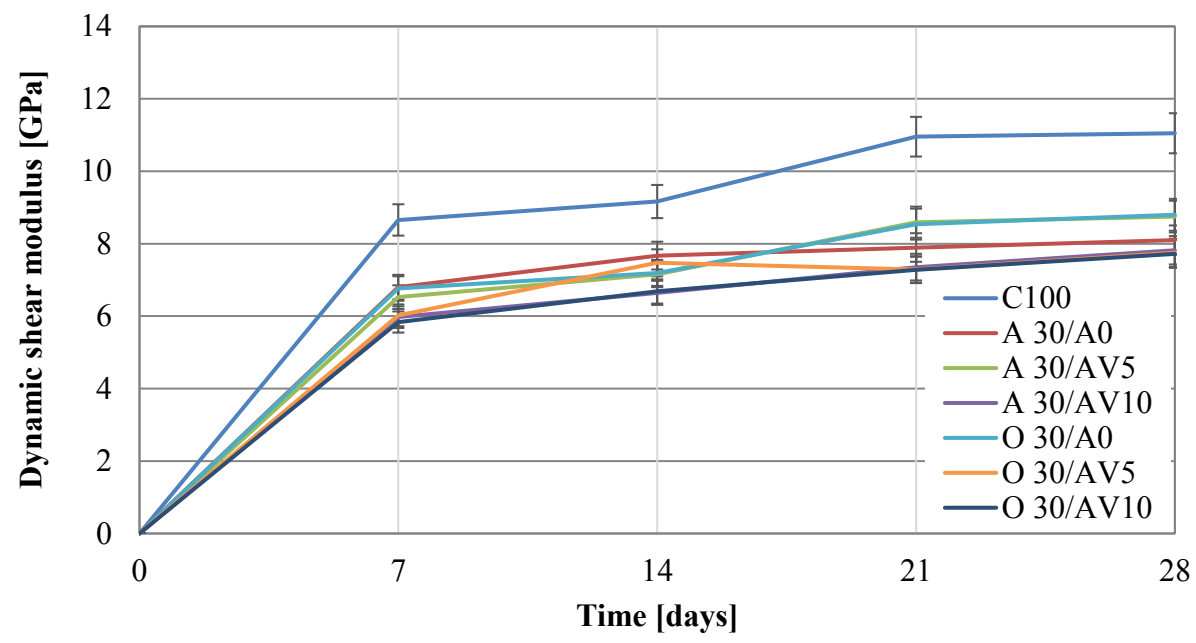

FIGURE 3. Development of dynamic shear modulus of the samples with slaked lime.

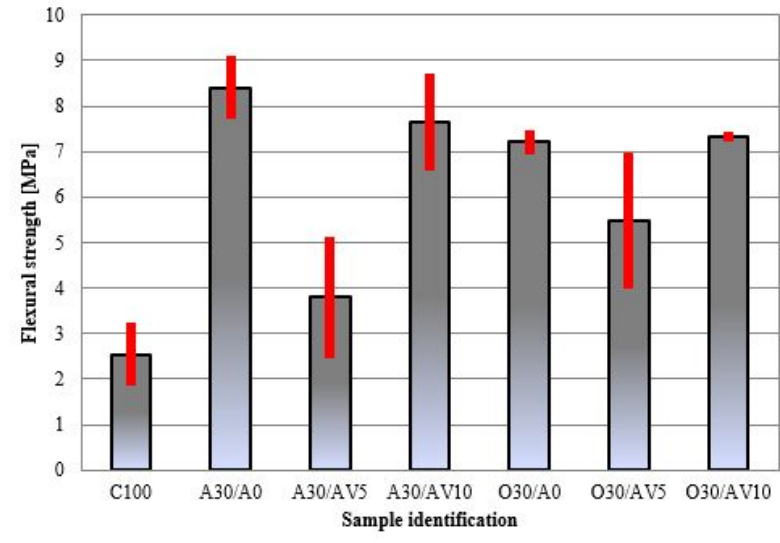

Figure 4. Flexural strength of the samples with slaked lime.

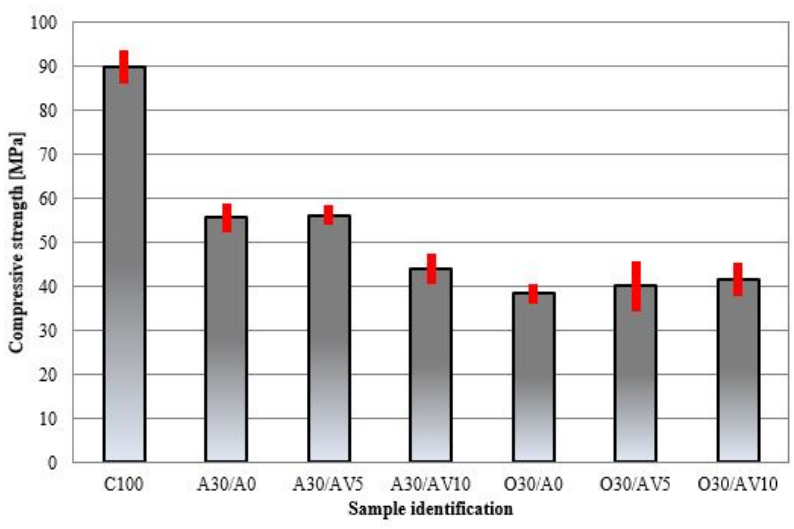

FiguRE 5. Compressive strength of the samples with slaked lime.

slaked lime had a positive effect on final properties.

At the end of the first phase, all samples were tested with destructive methods. The final flexural strength is shown in Figure 4. We can see a significant positive effect of blast furnace slag on flexural strength. In some cases, values were almost tripled. In general, slag has a much slower reaction and produces less heat. It needs time to react appropriately. For these reasons, the concrete based on slag is used for a long time. The influence of slaked lime was registered on the samples A 30/AV5 and O 30/AV5. Lower values of flexural strength suggest a more complex chemical reaction.

Figure 5 presents compressive strength and results overall confirmed previous conclusions. Mechanical activation had a positive effect on the final properties. Limited value of 5 wt. \% of slaked lime supported a chemical reaction and helped to increase compressive strength. Slag A was more finally ground and grains were more exposed. With slaked lime, we achieved the value $56 \mathrm{MPa}$. The positive effect of slaked lime is perceptible.

In the second phase, water-glass based on sodium and potassium was used to investigate its influence on final mechanical properties. Similar to the previous tests through 28 days period, dynamic Young's modulus and dynamic shear modulus were measured every week. As we can see in Figure 6 and Figure 7, the final values are more spread. Unfortunately, we can see a big difference between each samples. The reference sample had significantly higher values. The difference was approximately $5 \mathrm{GPa}$. The second highest value of dynamic Young's modulus and dynamic shear modulus had a sample A 30/A0 without any activator. By adding a water-glass as an activator, the final values were even more reduced. With more activator, the value drop was more obvious. The lowest values had samples with the highest amount of waterglass, regardless of sodium or potassium. The highest progress was also measured in the first 7 days. Later development was almost completely stopped and dynamic shear modulus was even decreased in the last week. Water-glass seemed unusable and negative effect was significant.

The destructive tests confirmed the results of the resonance tests. Flexural strength of the samples 


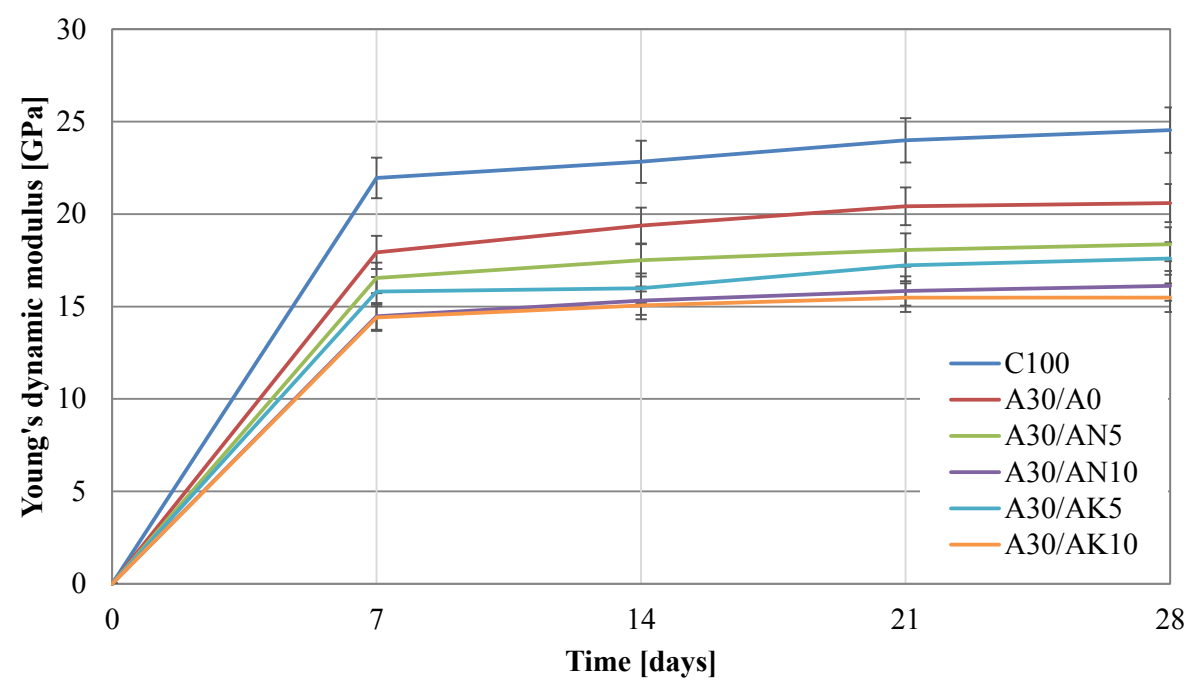

Figure 6. Development of dynamic Young's modulus of the samples with water-glass.

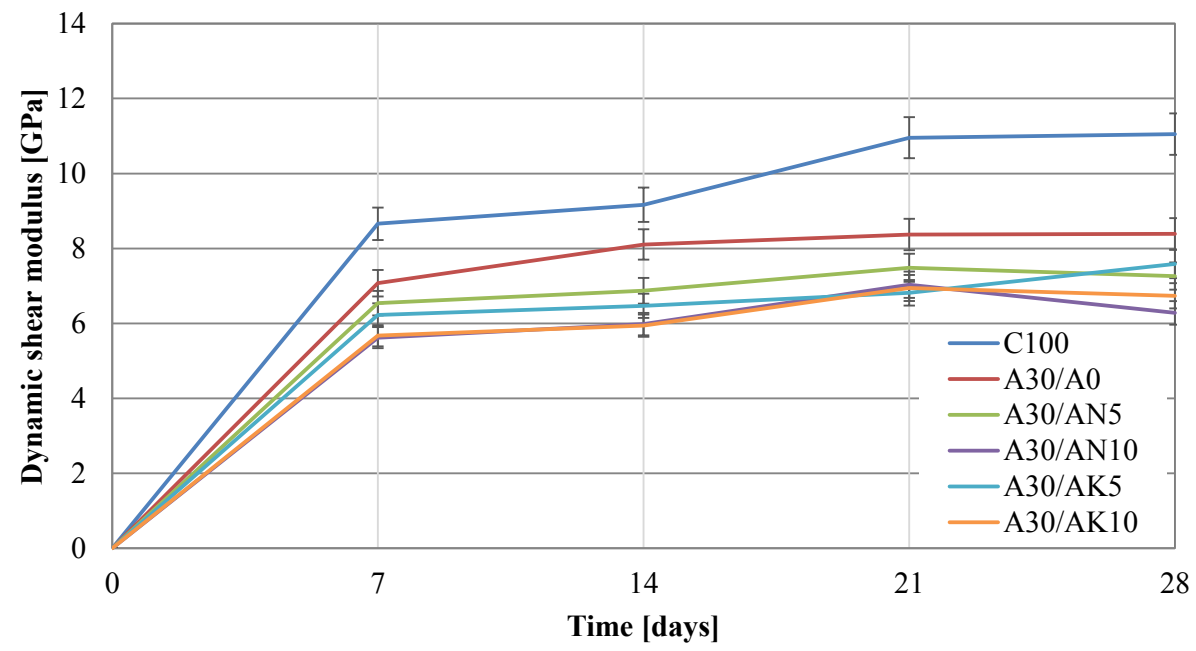

FIGURE 7. Development of dynamic shear modulus of the samples with water-glass.

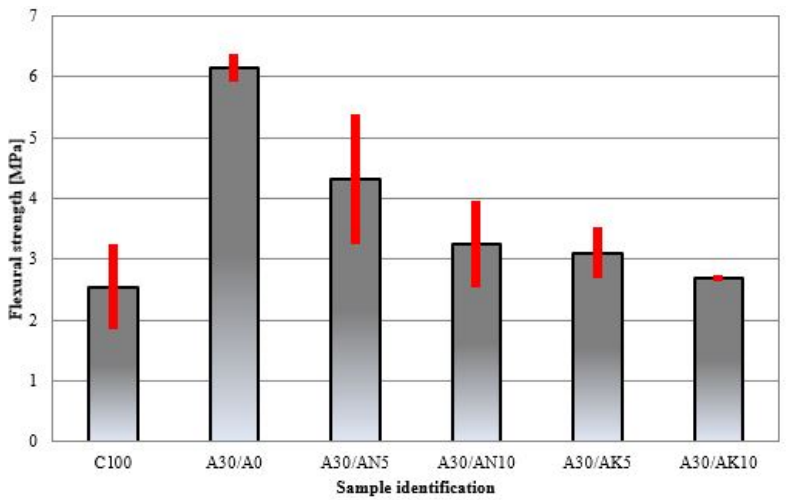

FiguRE 8. Flexural strength of the samples with water-glass.

with water-glass was reduced. With a higher amount of water-glass, the flexural strength drop was even more significant. Figure 8 shows the final results and values of flexural strength. The sample A 30/AK10 with 10 wt. $\%$ of water-glass based on potassium had

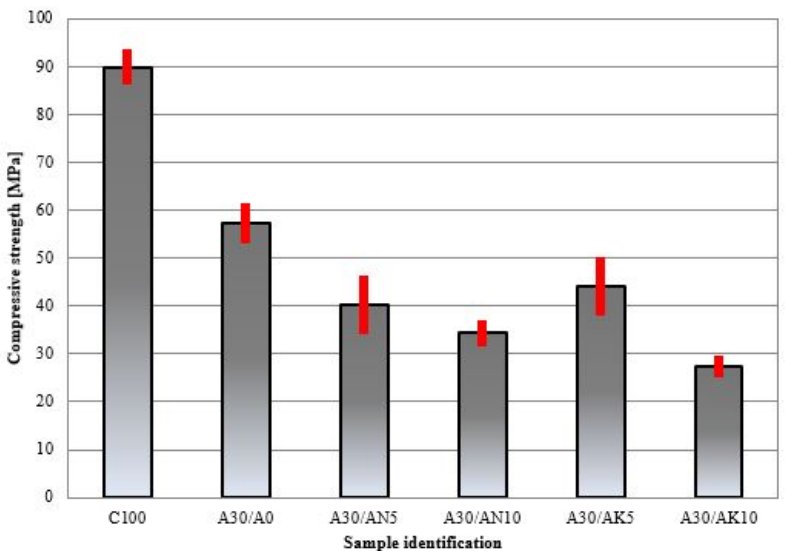

FiguRE 9. Compressive strength of the samples with water-glass.

almost the same flexural strength as the reference sample C 100 with 100 wt. \% of Portland cement. The negative effect of water glass almost removed the influence of the blast furnace slag. 
Compressive strength shown on Figure 9 proved water-glass does not work as an activator. The samples with water-glass had significantly reduced compressive strength. It seemed water-glass partially prevents the chemical reaction. The cement and blast furnace slag grains could not create a proper connection. The sample A 30/AK10 had the compressive strength reduced almost on half compared to the sample A 30/A0 and less than third compared to the sample C 100 only with Portland cement. Unfortunately, the result of the whole second phase was a complete failure. Water-glass can not be used as the activator.

\section{Conclusions}

This study investigated the influence of mechanical and chemical activation of the blast furnace slag to support a possibility of cement replacement up to the level of 35 wt. \%. Another goal was to find an ideal chemical activator and determine synergy between mechanical and chemical activation. Based on the results, it can be concluded that:

- Blast furnace slag had a positive effect on flexural strength.

- Highly carbonated blast furnace slag can be used as a binder to replace Portland cement.

- Mechanical and chemical activation created a synergy and supported the hydration process.

- Slaked lime worked as an activator but at a limited amount of 5 wt. $\%$.

- Water-glass did not work as an activator and even significantly reduced the influence of blast furnace slag regardless of sodium or potassium.

\section{ACKnowledgements}

This paper was financially supported by Czech Technical University in Prague under No. SGS project SGS19/148/OHK1/3T/11. The authors also thank Lavaris Ltd. for the supplied materials.

\section{REFERENCES}

[1] F. Bellmann, J. Stark. Activation of blast furnace slag by a new method. Cement and Concrete Research
39(8):644-650, 2009.

DOI:10.1016/j.cemconres.2009.05.012.

[2] W. S. Yum, J. I. Suh, D. Jeon, J. E. Oh. Strength enhancement of $\mathrm{CaO}$-activated slag system through addition of calcium formate as a new auxiliary activator. Cement and Concrete Composites 109:103572, 2020. DOI:10.1016/j.cemconcomp.2020.103572.

[3] Y. Jeong, H. Park, Y. Jun, et al. Influence of slag characteristics on strength development and reaction products in a $\mathrm{CaO}$-activated slag system. Cement and Concrete Composites 72:155-167, 2016. DOI:10.1016/j.cemconcomp.2016.06.005.

[4] Y. Wang, X. He, Y. Su, et al. Efficiency of wet-grinding on the mechano-chemical activation of granulated blast furnace slag (GBFS). Construction and Building Materials 199:185-193, 2019. DOI:10.1016/j.conbuildmat.2018.11.245.

[5] J. I. Escalante-García, A. F. Fuentes, A. Gorokhovsky, et al. Hydration products and reactivity of blast-furnace slag activated by various alkalis. Journal of the American Ceramic Society 86(12):2148-2153, 2003. DOI:10.1111/j.1151-2916.2003.tb03623.x.

[6] K. Sobolev. Mechano-chemical modification of cement with high volumes of blast furnace slag. Cement and Concrete Composites 27(7-8):848-853, 2005. DOI:10.1016/j.cemconcomp.2005.03.010.

[7] J. Trejbal, Z. Prošek, P. Tesárek, J. Valentin. Activation of blast furnace slag and its usage in practise. Týden výzkumu a inovací pro praxi 20192019.

[8] ASTM 1876-01. Standard Test Method for Dynamic Young's Modulus, Shear Modulus, and Poisson's Ratio by Impulse Excitation of Vibration, Annual Book of ASTM Standards, American Society for Testing and Materials 2006.

[9] ČSN 73 1372. In Non-destructive testing of concrete - Testing of concrete by resonance method, Czech office for standarts, metrology and testing. 2012.

[10] J. Topič, Z. Prošek. Properties and microstructure of cement paste including recycled concrete powder. Acta Polytechnica 57(1):49-57, 2017.

[11] ČSN EN 12390 (731302). In Testing hardened concrete, Czech office for standarts, metrology and testing. 2013.

[12] J. Kot'átková, J. Zatloukal, P. Reiterman, K. Kolář. Concrete and cement composites used for radioactive waste deposition. Journal of environmental radioactivity 178:147-155, 2017. 